\title{
Original
}

\section{Nanofilled and conventional resin-modified glass ionomer fillings combined with connective tissue grafts for treatment of gingival recessions with non-carious cervical lesions}

\author{
Erhan Dursun1), Güliz N. Güncü1), Ceyda K. Dursun1), Arlin Kiremitçi2), \\ Erdem Karabulut ${ }^{3)}$, and Ferda A. Akalın1) \\ 1)Department of Periodontology, Faculty of Dentistry, Hacettepe University, Ankara, Turkey \\ 2)Department of Restorative Dentistry, Faculty of Dentistry, Hacettepe University, Ankara, Turkey \\ 3)Department of Biostatistics, Faculty of Medicine, Hacettepe University, Ankara, Turkey \\ (Received May 10, 2017; Accepted October 13, 2017)
}

\begin{abstract}
The aim of this study was to evaluate the clinical root coverage results of subepithelial connective tissue grafts (SCTG) performed on teeth with gingival recessions and non-carious cervical lesions (NCCLs) that were restored with cervical fillings and compare the results of two different filling materials: resin-modified glass ionomer (RMGIC) and nanoionomer cements (NIC). A total of 54 teeth with Miller Class I gingival recessions with or without NCCLs in 36 patients ( 28 females, 8 males) were treated with SCTGs. Cervical lesions were randomly treated with RMGIC or NIC restorations. Periodontal clinical parameters, height of gingival recession (HGR), width of gingival recession (WGR), height of keratinized tissue, and dentin sensitivity were measured at baseline and 3, 6, and 12 months postoperatively. HGR and WGR values were statistically significantly reduced at all time points when compared to baseline values in all groups. There were no statistically significant differences between the groups in any clinical periodontal parameter $(P>\mathbf{0 . 0 5})$. The percentage of root coverage at 12 months was $89.5 \%, 90.1 \%$, and $96.2 \%$
\end{abstract}

Correspondence to Dr. Erhan Dursun, Department of Periodontology, Faculty of Dentistry, Hacettepe University, Sihhiye, Ankara 06100, Turkey

Fax: +90-312-310 4440 E-mail: erhandursundt@yahoo.com

J-STAGE Advance Publication: August 25, 2018

Color figures can be viewed in the online issue at J-STAGE.

doi.org/10.2334/josnusd.17-0190

DN/JST.JSTAGE/josnusd/17-0190 in the RMGIC, NIC, and control groups, respectively. Successful root coverage with connective tissue grafts may be achieved on teeth restored with RMGIC or NIC cervical fillings.

Keywords: Gingival recession; cervical lesion; cervical filling; root coverage; connective tissue graft; resin-modified glass ionomer filling; nanofilled glass ionomer.

\section{Introduction}

Gingival recession is defined as the apical shift of the gingival margin with exposure of the root surface (1). Many factors have been suggested as the cause of marginal tissue recession including plaque-induced inflammation, toothbrush trauma, tooth alignment, orthodontics, and restorative procedures. Gingival recession may lead to esthetic problems, dentin hypersensitivity, root caries, and non-carious cervical lesions (NCCLs) (2). In many cases, cervical lesions may exist and involve both the crown and the exposed root, causing the disappearance of the anatomic cementoenamel junction (CEJ) (3). Miller recessions are categorized as Class I and II when there is no loss of bone or soft tissue in the proximal area of the affected tooth and $100 \%$ root coverage can be anticipated in these cases. Many studies have confirmed that Miller Class I and II recessions can be predictably covered by soft tissue after techniques such as coronally advanced flaps (CAF), connective tissue grafts (CTG), and other pedicle flaps (1). 
NCCLs are described as wear of the tooth structure at the level of the gingival one-third of the tooth due to reasons other than dental caries $(4,5)$. NCCLs can involve only the crown of the tooth (enamel and/or coronal dentin) or only the root surface (cementum and/ or root dentin) or they can occupy both the crown and exposed root. NCCLs involving the root are commonly associated with gingival recession (6). In such cases, traditional mucogingival surgical techniques without any restorative treatment would not effectively achieve complete coverage (7); therefore, the combination of an adhesive restorative material and a mucogingival surgical approach might be a solution (8). The ideal treatment of NCCL involving the crown and the root should involve combined restorative and periodontal treatment (6).

Resin ionomer materials have many properties that allow the successful restoration of NCCLs and those in the subgingival area (9-11) including self-adhesion to dentin and enamel, epithelial and connective tissue adherence, better mechanical strength, and smoother surface than conventional glass ionomers (10). Epithelial and connective tissue adherence to resin ionomer restorative materials is observed during the healing process (10). Gingival recessions associated with NCCLs can be treated successfully with a glass ionomer restoration combined with a coronally advanced flap, with or without a connective tissue graft (12). It has been reported that subgingival sites in patients with large root lesions restored with resin-modified glass ionomer cements presented clinically healthy periodontal tissues that were well adapted to the root surface with no bleeding on probing (BOP) and minimum sulcus depth (10). Additionally, histological evaluations demonstrated fibroblast and connective tissue adhesion to the restorations (10). Recent studies investigating different restorative materials (resin-modified glass ionomer or microfilled resin composite) that could be used on exposed root surfaces affected by deep caries or cervical abrasions prior to surgical coverage showed clinically and histologically successful results $(13,14)$.

Nanotechnology is one of the most advanced areas for current research and is integrated in all disciplines for the development of biosynthetic and user-friendly materials using nanoparticles (15). Nanomedicine is defined as the science of preventing, diagnosing, and treating diseases and preserving and improving human health with the use of nanotechnology (16). Developments in the field of resin-modified glass ionomer cement (RMGIC) using nanotechnology have led to the introduction of nano-ionomer cements (NIC), which have the combined benefits of RMGIC and nanosized $\left(10^{-9} \mathrm{~m}\right)$ particles
(17). The major innovation of this material involves the incorporation of nanotechnology, which allows highly packed filler composition (69\%), of which approximately two-thirds are nanofillers (18). Major advantages of nanoionomer filling are better polishability and smoother surface texture (19).

The null hypothesis tested in the present study was that comparable root coverage and esthetic results would be achieved after performance of SCTG + CAF on teeth presenting with gingival recessions without NCCLs or with NCCLs that were restored with cervical fillings. A secondary aim was to compare the results of the fillings made with either conventional RMGIC or NIC.

\section{Materials and Methods}

\section{Study groups}

A total of 54 teeth in 36 patients ( 28 females, 8 males, mean age $41.65 \pm 12.26$ years) with Miller Class I gingival recessions were included in the study. The test groups had teeth presenting with gingival recessions combined with NCCLs, while the control group was composed of teeth with only gingival recessions. The participants were selected among patients who were referred to Hacettepe University, Faculty of Dentistry, Department of Periodontology, for periodontal treatment. All procedures performed in studies involving human participants were in accordance with the ethical standards of the institutional and/or national research committee and with the 1964 Declaration of Helsinki and its later amendments or comparable ethical standards. Approval was obtained from the Local Ethics Committee of Hacettepe University (Decision number: HEK 09/249/49). Informed consent was obtained from all participants included in the study.

The study included those who were non-smokers, had no systemic disease, had no contraindication for periodontal surgery, had not taken medications known to restrict wound healing, presented with Miller Class I gingival recessions associated with NCCLs in maxillary or mandibular anterior or premolar teeth, with probing depth (PD) $<3 \mathrm{~mm}$ and no BOP, had no root canal treatment and absence of restoration and severe occlusal interferences, and had no previous periodontal surgery in the area to be treated. Recession defects associated with evidence of pulpal pathology as well as molar teeth were not included. Bearing in mind that NCCL may be due to a multifactorial process, including tooth structure loss caused by nonbacterial acids (erosion), traumatic tooth brushing (abrasion), or occlusal loading (abfraction), all subjects were enrolled in a pretreatment program to eliminate the possible etiologic factors related to NCCL and gingival recession. The pretreatment program included 
Table 1 Materials used in the present study

\begin{tabular}{llll}
\hline Material & Manufacturer & Composition & Batch No. \\
\hline Ketac N-100 (NIC) & $3 \mathrm{M} \mathrm{ESPE}$ & $\begin{array}{l}\text { Paste RMGI Filling: methacrylate polyacid, } \\
\text { water, FAS glass, nanofillers, methacrylate } \\
\text { monomers, initiators }\end{array}$ & N097903 \\
$\begin{array}{lll}\text { Ketac N-100 Nano- } \\
\text { ionomer primer }\end{array}$ & $3 \mathrm{M} \mathrm{ESPE}$ & $\begin{array}{l}\text { RMGI Primer: methacrylate polyacid, } \\
\text { water, methacrylate monomers, initiators }\end{array}$ & 9BF \\
$\begin{array}{l}\text { Vitremer (RMGIC) } \\
\text { 3M ESPE }\end{array}$ & $\begin{array}{l}\text { Powder/Liquid RMGI Filling: methacrylate } \\
\text { polyacid, water, FAS glass, methacrylate } \\
\text { monomers, initiators }\end{array}$ & $\begin{array}{l}\text { Powder: 6LY } \\
\text { Liquid: 6FJ }\end{array}$ \\
& 3M ESPE & HEMA, Vitrebond copolymer, ethyl alcohol & 6BJ \\
\hline $\begin{array}{l}\text { Vitremer primer } \\
\text { RMGIC: resin-modified glass ionomer cement, }\end{array}$ & NIC: Nano-ionomer cement, HEMA: 2-hydroxyethyl methacrylate
\end{tabular}

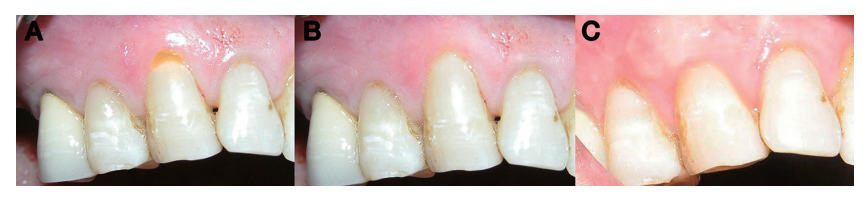

Fig. 1 A: Preoperative view of cervical lesions, B: After RMGIC restoration, $\mathrm{C}: 12$ months after the $\mathrm{CTG}+\mathrm{CAF}$ procedure.

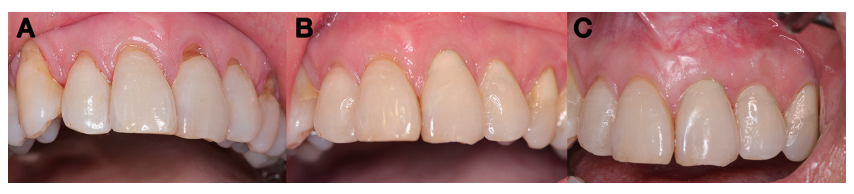

Fig. 2 A: Preoperative view of cervical lesions, B: After NIC restoration, $\mathrm{C}: 12$ months after the $\mathrm{CTG}+\mathrm{CAF}$ procedure.

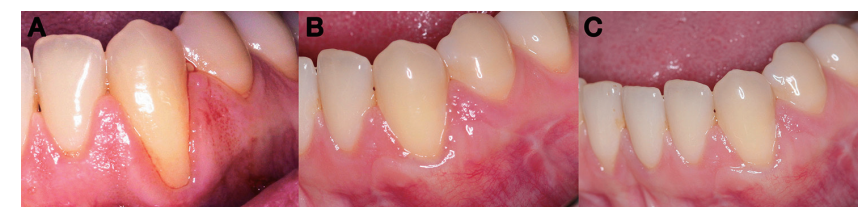

Fig. 3 A: Preoperative view of gingival recession in the control group, B: 3 months after the $\mathrm{CTG}+\mathrm{CAF}$ procedure, $\mathrm{C}: 12$ months after the $\mathrm{CTG}+\mathrm{CAF}$ procedure.

scaling, root planning, and crown polishing. Oral hygiene instructions including a non-traumatic brushing technique and soft toothbrush were also provided in the pretreatment program. The participants were instructed to avoid excessive consumption of acidic beverages or foods.

We evaluated three groups in the present study: resinmodified glass ionomer cement filling group (RMGIC, Vitremer, 3M ESPE, St. Paul, MN, USA), nano-ionomer cement filling group (NIC, Ketac N-100; 3M ESPE, Seefeld, Germany) (test groups), and the control group without NCCL (Table 1). Each group included 18 teeth with Miller Class I gingival recessions. In the test groups, NCCLs were restored with either RMGIC or NIC filling materials. For Vitremer restorations, the primer was applied to the cavity for $30 \mathrm{~s}$ and dried using an air syringe for approximately $15 \mathrm{~s}$. Next, the dried primed surfaces were light cured for $20 \mathrm{~s}$ and appeared glossy after light curing. The powder and liquid were mixed according to the manufacturer's instructions (Table 1). For Ketac $\mathrm{N}-100$ restorations, primer was applied to the cavity for $15 \mathrm{~s}$ and dried using an air syringe for $10 \mathrm{~s}$, and the dried primed surfaces were light cured for $10 \mathrm{~s}$. Paste A and paste $\mathrm{B}$ were dispensed on a mixing pad using a Clicker
Dispenser. Mixed cement was loaded into a delivery tip and syringed into the cavity by keeping the syringe tip immersed in the material to minimize air entrapment. The restoration was condensed and contoured with a plastic filling instrument and cured for $40 \mathrm{~s}$ immediately after curing restoration was finished and polished using aluminum oxide disks of decreasing abrasiveness (SofLex; 3M ESPE) (Table 1).

CTG combined with coronally positioned flap were performed after the fillings were done (Figs. 1, 2). In the control group, only the CTG combined with coronally positioned flap were performed on teeth with only gingival recession (Fig. 3).

\section{Clinical evaluations}

After the initial therapy, the following parameters were recorded as baseline measurements: 1) PD: distance from the gingival margin to the base of the gingival crevice; 2) Clinical attachment level (CAL): $\mathrm{PD}+$ height of gingival recession; 3) Gingival index (GI) (20); 4) Presence or absence of BOP at the site; 5) Plaque index (PI) $(20)$; 6) Height of gingival recession (HGR): measured as the distance from the CEJ to the gingival margin; clinical CEJ was estimated by the method established by 
Zucchelli et al. (2006) (3); 7) Width of gingival recession (WGR); 8) Height of keratinized tissue (HKT): measured as the distance from the gingival margin to the mucogingival junction; 9) Keratinized tissue thickness (KTT): measured at the midpoint between the gingival margin and mucogingival junction using an endodontic spreader, and a silicone stop was placed in contact with the soft tissue surface once the spreader reached a hard surface $(\mathrm{KTT}=$ distance from the endodontic spreader tip to the silicone stop as measured with a digital caliper); 10) Height of cervical lesion (HCL): measured as the distance between the coronal and apical margins of the NCCL; 11) Width of cervical lesion (WCL): measured as the distance between the mesial and distal margins of the NCCL; 12) Dentin sensitivity (DS): recorded according to the answers of the participants regarding the presence or absence of cervical hypersensitivity in the related teeth; and 13) Esthetic score (ES): recorded according to Cairo et al. (21). Marginal tissue contour, soft tissue texture, mucogingival junction alignment, and gingival color values were evaluated, and points were given to these parameters. The ideal ES was 10 (21).

NCCLs were treated randomly with RMGIC or NIC restorations. Randomization was performed by computer-generated numbers in sealed opaque envelopes by the specialist who restored all NCCLs (AK). Prior to the study, the examiner (CKD) measured the PD and HGR of all patients two times within $24 \mathrm{~h}$, with at least $1 \mathrm{~h}$ between examinations. The intra-examiner $\mathrm{k}$ index resulted in $89 \%$ agreement for PD and HGR. Masking of the examiner was not possible due to the possibility to observe which restorative material was used.

\section{Surgical procedure}

All surgical procedures were done 10 days after the restoration procedures. The surgical procedure was performed using the Langer and Langer technique (22). After local anesthetic administration, the incision at the coronal margin of the flap was started with a horizontal intrasulcular incision at the buccal aspect of the involved tooth. Two horizontal incisions were made at right angles to the adjacent interdental papillae $1 \mathrm{~mm}$ apical to the coronal border of the NCCL. Two vertical incisions were placed at least one-half to one tooth wider mesiodistally than the area of gingival recession and were extended beyond the mucogingival junction. A trapezoidal split thickness flap was raised, the area was irrigated with sterile saline solution, and the epithelium on the adjacent papillae was stripped away. Preparation of the donor site involved placing the incisions between the distal aspect of the canine and the midpalatal region of the first molar area using the parallel incision technique or the trap-door technique. A SCTG of adequate size and $2 \mathrm{~mm}$ thickness was harvested. The donor site was sutured with silk 4-0 sling sutures. At the recipient site, the SCTG was placed under the flap, which was positioned coronally (CAF) and sutured with silk 5-0 simple loop sutures.

\section{Statistical analysis}

The study power was calculated using PC-SIZE software (Dallal GE, Boston, MA, USA) considering the standard deviation of each group prior to the study. A difference of $1 \mathrm{~mm}$ in gingival recession and CAL between the groups was considered clinically significant. This analysis indicated that the study would have $>80 \%$ power to detect a $1 \mathrm{~mm}$ difference in gingival recession and CAL for intergroup comparison with 18 subjects in each group (11). SPSS statistical software for Windows, version 16 (SPSS Inc., Chicago, IL, USA) was used for data analysis, and Fisher exact test was used to analyze the qualitative variables in the three groups. Normality of data was analyzed by the Shapiro-Wilk test; normally distributed baseline and changes $(\Delta)$ data were analyzed by one-way ANOVA test, and intergroup pairwise comparisons were done using the Duncan test when statistically significant differences were found. The changes $(\Delta)$ in data, which were not normally distributed, were analyzed by KruskalWallis test, and pairwise comparisons were done by Dunn test when statistically significant differences were found. Comparisons of normally distributed data within the groups were assessed by repeated measures ANOVA, and pairwise comparisons were done using the Bonferroni test. Furthermore, Friedman test and pairwise Dunn test were used for non-normally distributed variables.

\section{Results}

A total of 54 Miller Class I gingival recession defects (36 with NCCL, 18 without NCCL) were treated with SCTG $+\mathrm{CAF}$, and no patient experienced healing complications or adverse events. In the present study, 22 patients had one tooth, 10 patients had two teeth, 3 patients had three teeth, and 1 patient had four teeth with gingival recessions associated with or without NCCLs.

\section{Cervical lesion parameters}

The mean baseline HCLs in the RMGIC and NIC groups were $4.39 \pm 0.91 \mathrm{~mm}$ and $4.28 \pm 1.22 \mathrm{~mm}$, respectively. The mean baseline WCL was $3.00 \pm 0.76 \mathrm{~mm}$ for the RMGIC group and $3.5 \pm 1.2 \mathrm{~mm}$ for the NIC group. Patients in the control group had no cervical lesions. There were no statistically significant differences between the test groups according to the baseline CA measurements 
Table 2 Gingival recession and keratinized tissue parameters

\begin{tabular}{|c|c|c|c|c|c|c|c|c|c|c|c|c|}
\hline & \multicolumn{3}{|c|}{ BASELINE } & \multicolumn{3}{|c|}{3 months } & \multicolumn{3}{|c|}{6 months } & \multicolumn{3}{|c|}{12 months } \\
\hline & RMGIC & NIC & $\mathrm{C}$ & RMGIC & NIC & $\mathrm{C}$ & RMGIC & NIC & $\mathrm{C}$ & RMGIC & NIC & $\mathrm{C}$ \\
\hline HGR & $3.5 \pm 1.04$ & $3.13 \pm 0.68$ & $3.17 \pm 0.85$ & $0.44 \pm 0.70^{*}$ & $0.24 \pm 0.56^{*}$ & $0.06 \pm 0.23^{*}$ & $0.44 \pm 0.7^{*}$ & $0.24 \pm 0.56^{*}$ & $0.06 \pm 0.23^{*}$ & $0.44 \pm 0.7^{*}$ & $0.41 \pm 0.71^{*}$ & $0.06 \pm 0.23^{*}$ \\
\hline WGR & $3.28 \pm 0.75$ & $3.06 \pm 0.68$ & $3,00 \pm 0.48$ & $0.72 \pm 1.07^{*}$ & $0.41 \pm 1.0^{*}$ & $0.17 \pm 0.7^{*}$ & $0.78 \pm 1.16^{*}$ & $0.41 \pm 1.00^{*}$ & $0.17 \pm 0.7^{*}$ & $0.78 \pm 1.16^{*}$ & $0.65 \pm 1.16^{*}$ & $0.17 \pm 0.17^{*}$ \\
\hline HKT & $2.83 \pm 1.85$ & $3.28 \pm 1.56$ & $2.62 \pm 1.19$ & $4.94 \pm 1.89^{*}$ & $5.92 \pm 1.44^{*}$ & $5.12 \pm 1.16^{*}$ & $4.89 \pm 1.84^{*}$ & $5.62 \pm 0.96^{*}$ & $5.12 \pm 1.16^{*}$ & $4.89 \pm 1.84^{*}$ & $5.62 \pm 0.96^{*}$ & $5.12 \pm 1.16^{*}$ \\
\hline KTT & $1.22 \pm 0.54$ & $1.06 \pm 0.23$ & $1.28 \pm 0.57$ & & & & & & & $2.30 \pm 0.08^{*}$ & $2.16 \pm 0.16^{*}$ & $2.36 \pm 0.18^{*}$ \\
\hline
\end{tabular}

Table 3 Changes $(\Delta)$ of gingival recession and keratinized tissue parameters

\begin{tabular}{lccc}
\hline & \multicolumn{3}{c}{$\Delta 12$ months } \\
\cline { 2 - 4 } & RMGIC & NIC & C \\
\hline HGR & $3.22 \pm 0.66$ & $3.08 \pm 0.71$ & $3.16 \pm 0.20$ \\
WGR & $2.81 \pm 1.29$ & $3.06 \pm 1.16$ & $2.83 \pm 1.04$ \\
HKT & $2.19 \pm 0.73$ & $2.26 \pm 0.69$ & $2.43 \pm 1.17$ \\
\hline
\end{tabular}

RMGIC: resin-modified glass ionomer cement, NIC: nano-ionomer cements, C: control, HGR: height of gingival recession, WGR: width of gingival recession, HKT: height of keratinized tissue.

Table 4 Root coverage and CAL gain at 12 month follow-up

\begin{tabular}{lcccc}
\hline 12 months & RMGIC & NIC & C & $P$ \\
\hline RC $(\%)$ & $89.49 \pm 18.15$ & $90.12 \pm 16.58$ & $96.22 \pm 10.75$ & 0.13 \\
CAL gain $(\mathrm{mm})$ & $1.66 \pm 0.76$ & $1.61 \pm 0.47$ & $1.35 \pm 0.76$ & 0.14 \\
\hline
\end{tabular}

RMGIC: resin-modified glass ionomer cement, NIC: nano-ionomer cement, C: control, RC: root coverage, CAL gain: clinical attachment level gain.

Table 5 Clinical indices of the study groups

\begin{tabular}{|c|c|c|c|c|c|c|c|c|c|c|c|c|}
\hline & \multicolumn{3}{|c|}{ Baseline } & \multicolumn{3}{|c|}{3 months } & \multicolumn{3}{|c|}{6 months } & \multicolumn{3}{|c|}{12 months } \\
\hline & RMGIC & NIC & $\mathrm{C}$ & RMGIC & NIC & C & RMGIC & NIC & $\mathrm{C}$ & RMGIC & NIC & $\mathrm{C}$ \\
\hline $\mathrm{PD}$ & $1.73 \pm 0.64$ & $1.21 \pm 0.03$ & $1.45 \pm 0.61$ & $1.63 \pm 0.40$ & $1.45 \pm 0.56$ & $1.5 \pm 0.55$ & $1.61 \pm 0.35$ & $1.37 \pm 0.43$ & $1.43 \pm 0.44$ & $1.88 \pm 0.29$ & $1.28 \pm 0.39$ & $1.48 \pm 0.41$ \\
\hline CAL & $3.16 \pm 0.65$ & $3.03 \pm 0.78$ & $2.67 \pm 0.63$ & $1.47 \pm 0.76$ & $1.53 \pm 1.04$ & $1.16 \pm 0.64$ & $1.41 \pm 0.75$ & $1.53 \pm 0.96$ & $1.15 \pm 0.77$ & $1.76 \pm 0.76$ & $1.51 \pm 0.86$ & $1.25 \pm 0.57$ \\
\hline GI & $0.23 \pm 0.23$ & $0.18 \pm 0.33$ & $0.34 \pm 0.40$ & $0.06 \pm 0.14$ & $0.17 \pm 0.35$ & $0.26 \pm 0.33$ & $0.09 \pm 0.17$ & $0.14 \pm 0.28$ & $0.18 \pm 0.32$ & $0.06 \pm 0.17$ & $0.12 \pm 0.27$ & $0.12 \pm 0.22$ \\
\hline BOP & $0.38 \pm 0.80$ & $0.25 \pm 0.77$ & $0.88 \pm 1.14$ & $0.25 \pm 0.77$ & $0.44 \pm 1.03$ & $0.56 \pm 0.96$ & $0.38 \pm 0.88$ & $0.06 \pm 0.25$ & $0.62 \pm 1.08$ & $0.00 \pm 0.00$ & $0.00 \pm 0.00$ & $0.06 \pm 0.25$ \\
\hline PI & $0.17 \pm 0.25$ & $0.26 \pm 0.19$ & $0.37 \pm 0.52$ & $0.18 \pm 0.32^{*}$ & $0.42 \pm 0.33^{*}$ & $0.35 \pm 0.34$ & $0.20 \pm 0.27$ & $0.40 \pm 0.28$ & $0.34 \pm 0.47$ & $0.18 \pm 0.26^{*}$ & $0.48 \pm 0.39^{*}$ & $0.25 \pm 0.31$ \\
\hline
\end{tabular}

$(P=0.84$ for $\mathrm{HCL}$ and $P=0.18$ for $\mathrm{WCL})$.

\section{Within-Group Comparisons}

Statistically significant reductions were recorded in HGR, WGR, and HKT in all groups and at all time points when compared to baseline $(P<0.05)$, and significant improvements associated with root coverage percentage were detected at all time points $(P<0.05)$ (Tables $2,3,4)$. Additionally, KTT was significantly higher than baseline at 6 months $(P<0.05)$ (Table 2).

No significant differences were found in PD values between time points when periodontal parameters were evaluated in all groups $(P>0.05)$. A statistically significant CAL gain was recorded at the 3 rd month compared with baseline $(P<0.05)$, whereas no significant changes were observed between the other follow-up periods $(P>$ $0.05)$. BOP values did not change significantly between time points $(P>0.05)$.

In the RMGIC and NIC groups, PI values were significantly higher at all time points when compared to baseline, except in the 3rd month $(P<0.05)$. However, no statistically significant differences were found in PI values between time points in the control group (Table $5)$.

\section{Between group comparisons}

At baseline, there were no statistically significant differences between the groups in PD, CAL, GI, BOP, CA, PI, gingival recession, or keratinized tissue parameters $(P>$ $0.05)$. 
At 3, 6, and 12 months, there were no statistically significant differences between the groups at any followup time point in $\mathrm{PD}$, CAL gain, GI, BOP, PI, gingival recession, root coverage, or keratinized tissue parameters $(P>0.05)$ (Tables 3, 4, 5). The percentages of root coverage at 12 month follow-up were $89.49 \%, 90.12 \%$, and $96.22 \%$ in the RMGIC, NIC, and control groups, respectively (Table 5).

\section{Dentin sensitivity and esthetic score}

A total of 41 defects (11 from RMGIC, 17 from NIC, and 13 from control groups) (75.1\%) had DS at baseline, whereas no significant differences were found between the groups according to patient distribution at baseline $(P=0.06)$. When compared with baseline, a significant reduction in DS was seen in all groups at follow-up visits. Only 1 patient in the RMGIC group still complained about DS at 12 months, and there were no significant differences between groups regarding $\mathrm{DS}$ reduction $(\mathrm{P}=$ $0.66)$.

No statistically significant difference was detected between the groups when 12 month ES values were evaluated $(P>0.05)$. ES was similar in the RMGIC and NIC groups $(9.06 \pm 1.43)$ and was higher in the control group than in the test groups.

\section{Discussion}

The attachment of gingival tissue grafts on cervical restorations is a continuous topic of research. Although some clinical trials have made comparisons between restored and unrestored surfaces $(14,23)$, research on the most predictable treatment option is ongoing. Treatment decision making can be difficult due to factors such as the location, extension, and depth of the cervical lesion depending on the soft tissue defect (24). Recent studies have shown clinical and histological success investigating different restorative materials (RMGIC or microfilled resin composite) that could be used on exposed root surfaces affected by deep caries or NCCLs prior to surgical coverage with SCTG + CAF $(13,14)$.

The present study had two purposes: to clinically evaluate the root coverage results with CTG on cervical fillings and to compare the two different filling materials. For this purpose, SCTG + CAF was performed on teeth with Miller Class I gingival recessions and cervical fillings to determine the rate of root coverage on the cervical restorations, and the results of the conventional and nanofilled materials were compared. To evaluate the effect of fillings on the success rate, a control group with only gingival recession without cervical lesions treated with SCTG + CAF as gold standard recession treatment was also included in the study.

Root coverage percentages at 12 months were $89.49 \%, 90.12 \%$, and $96.22 \%$ for the RMGIC, NIC, and control groups, respectively. The highest percentage of root coverage was observed in the control group, and the coverage percent was higher in the NIC group than the RMGIC group although the difference was not significant. Based on our results, the minimum PD with successful CAL gain and root coverage in the area of recession in all groups may be evidence of new connective tissue attachment as has been reported in several other histological studies $(25,26)$. Previous histological evaluations showed fibroblast adhesion and connective tissue attachment to the restorations $(10,27,28)$. While the results of the present study regarding connective tissue attachment should be interpreted with caution due to lack of histological analysis, the clinical appearance of treatment outcomes (root coverage and CAL gain) may be considered as connective tissue attachment of grafts to cervical restorations.

The use of restorative materials for cervical lesions prior to surgical root coverage procedures has been proven in many studies. Santamaria et al. reported that the presence of RMGIC restoration under SCTG might not be an obstacle for soft tissue coverage (11). Lucchesi et al. reported successful root coverage improvement without periodontal tissue damage with the use of CPF for treatment of root surfaces restored with RMGIC and microfilled resin composite (23). Based on our findings in the present study, it can be assumed that, in accordance with Santamaria et al. (11), the presence of restoration in the cervical region may not prevent the soft tissue coverage that can be achieved by using the SCTG $+\mathrm{CAF}$ procedure. We found that that the RMGIC and NIC materials showed comparable amounts of root coverage when compared with the control group with no cervical lesion.

Different studies in the literature have evaluated the impact of restorative approaches on the periodontium. Some of these studies have reported that the subgingival portion of dental restorations may cause gingival inflammation as well as development of gingivitis and associated periodontitis by increasing local plaque accumulation (29,30). Dragoo (10), Alkan et al. (9), and Santamaria et al. (11) have reported good periodontal health with RMGIC when used in subgingival and transgingival restorations (9-11). In the present study, no site in any group showed BOP at any time point. Additionally, there were no significant differences in GI and PI values between the groups, which is in accordance with the above-mentioned studies suggesting the use of RMGIC for subgingival restorations. As in the RMGIC group, the 
NIC group showed no BOP or clinical signs of gingival inflammation to suggest material biocompatibility when used subgingivally. Additionally, it can be assumed that following up patients for monthly prophylaxis, plaque control, and oral hygiene instructions will ensure gingival health during the study period.

A DS evaluation was performed whereby patients were asked about the presence or absence of sensitivity before and after the root coverage procedures without any thermal and tactile stimulus. All groups showed significantly reduced DS between baseline and the subsequent observation periods, and no significant differences in DS reduction were found between the groups. Santamaria et al. reported better DS reduction in the RMGIC and CTG groups than in the CTG group (11). In the present study, ES values according to Cairo et al. were high in all groups but no significant differences were observed (21).

To investigate the hypothesis that the crown portion of the cervical lesion primarily composed the most coronal zone of the cervical lesion, an estimation of the position of the CEJ by the Zucchelli technique was performed (3). According to this method, a scalloped line representing attachment loss at the CEJ is drawn following the patient biotype and connecting the ideal dimension of the adjacent papilla. Due to the properties of Miller Class I defects, it was possible to estimate the CEJ and thereby height of gingival recession.

Several studies in the literature have shown successful treatments of cervical lesions associated with gingival recessions with RMGIC and CAF procedures with or without CTG $(9,11,23,24)$. In the present study, NIC was tested versus RMGIC for the restoration of cervical lesions before the root coverage procedure (SCTG + $\mathrm{CAF}$ ), and a control group without cervical lesion was chosen as a gold standard. To our knowledge, this is the first study in the literature to evaluate the effect of NIC in the treatment of gingival recession associated with NCCL. Resin ionomer materials have many properties (self-adhesion to dentin and enamel, epithelial and connective tissue adherence, better mechanical strength, and smoother surface compared to conventional glass ionomers) that allow them to be used successfully in the restoration of NCCLs and in the subgingival area (9-11). Alternatively, the major reported advantages of nanoionomer filling are better polishability and smoother surface texture (19). According to the present study, NIC was not superior to RMGIC; however, RMGIC and NIC materials showed comparable amounts of root coverage when compared with the control group with no cervical lesion. The smoother surface texture of both restorative materials would allow them to be successfully used for the treatment of NCCL-associated gingival recession prior to surgical coverage. Further studies with large samples and longitudinal observation are necessary to confirm the stability of the results of this combined approach in the treatment of these combined lesions.

In this study, the tested materials for NCCLs were conventional RMGIC and NIC restorations. We found that teeth with gingival recessions associated with NCCLs may be successfully treated with an integrated periodontal and restorative dentistry approach, and root coverage with CTG may be successfully obtained on cervical fillings.

\section{Conflict of interest}

The authors reported no conflict of interest related to the present study.

\section{References}

1. Wennström JL (1996) Mucogingival therapy. Ann Periodontol 1, 671-701.

2. Bouchard P, Malet J, Borghetti A (2001) Decision-making in aesthetics: root coverage revisited. Periodontol 2000 27, 97-120.

3. Zucchelli G, Testori T, De Sanctis M (2006) Clinical and anatomical factors limiting treatment outcomes of gingival recession: a new method to predetermine the line of root coverage. J Periodontol 77, 714-721.

4. Grippo JO, Simring M, Schreiner S (2004) Attrition, abrasion, corrosion and abfraction revisited: a new perspective on tooth surface lesions. J Am Dent Assoc 135, 1109-1118.

5. Bartlett DW, Shah P (2006) A critical review of non-carious cervical (wear) lesions and the role of abfraction, erosion, and abrasion. J Dent Res 85, 306-312.

6. Zucchelli G, Gori G, Mele M, Stefanini M, Mazzotti C, Marzadori M et al. (2011) Non-carious cervical lesions associated with gingival recessions: a decision-making process. J Periodontol 82, 1713-1724.

7. Camargo PM, Lagos RA, Lekovic V, Wolinsky LE (2001) Soft tissue root coverage as treatment for cervical abrasion and caries. Gen Dent 49, 299-304.

8. Anson D (1999) Periodontal esthetics and soft-tissue root coverage for treatment of cervical root caries. Compend Contin Educ Dent 20, 1043-1046, 1048-1050, 1052; quiz 1054.

9. Alkan A, Keskiner I, Yuzbasioglu E (2006) Connective tissue grafting on resin ionomer in localized gingival recession. J Periodontol 77, 1446-1451.

10. Dragoo MR (1997) Resin-ionomer and hybrid-ionomer cements: part II, human clinical and histologic wound healing responses in specific periodontal lesions. Int J Periodontics Rest Dent 17, 75-87.

11. Santamaria MP, Ambrosano GM, Casati MZ, Nociti Júnior FH, Sallum AW, Sallum EA (2009) Connective tissue graft plus resin-modified glass ionomer restoration for the treat- 
ment of gingival recession associated with non-carious cervical lesion: a randomized-controlled clinical trial. J Clin Periodontol 36, 791-798.

12. Santamaria MP, Suaid FF, Nociti FH Jr, Casati MZ, Sallum AW, Sallum EA (2007) Periodontal surgery and glass ionomer restoration in the treatment of gingival recession associated with a non-carious cervical lesion: report of three cases. J Periodontol 78, 1146-1153.

13. Martins TM, Bosco AF, Nóbrega FJ, Nagata MJ, Garcia VG, Fucini SE (2007) Periodontal tissue response to coverage of root cavities restored with resin materials: a histomorphometric study in dogs. J Periodontol 78, 1075-1082.

14. Santamaria MP, Suaid FF, Casati MZ, Nociti FH, Sallum AW, Sallum EA (2008) Coronally positioned flap plus resin-modified glass ionomer restoration for the treatment of gingival recession associated with non-carious cervical lesions: a randomized controlled clinical trial. J Periodontol 79, 621-628.

15. Fayaz AM, Balaji K, Girilal M, Yadav R, Kalaichelvan PT, Venketesan R (2010) Biogenic synthesis of silver nanoparticles and their synergistic effect with antibiotics: a study against gram-positive and gram-negative bacteria. Nanomedicines 6, 103-109.

16. Kubik T, Bogunia-Kubik K, Sugisaka M (2005) Nanotechnology on duty in medical applications. Curr Pharm Biotechnol 6, 17-33.

17. Upadhyay S, Rao A (2011) Nanoionomer: evaluation of microleakage. J Indian Soc Pedod Prev Dent 29, 20-24.

18. Coutinho E, Cardoso MV, De Munck J, Neves AA, Van Landuyt KL, Poitevin A et al. (2009) Bonding effectiveness and interfacial characterization of a nano-filled resin-modified glass-ionomer. Dent Mater 25, 1347-1357.

19. Perdigão J, Dutra-Corrêa M, Saraceni SHC, Ciaramicoli MT, Kiyan VH (2012) Randomized clinical trial of two resinmodified glass ionomer materials: 1-year results. Oper Dent 37, 591-601.

20. Silness J, Loe H (1964) Periodontal disease in pregnancy. II. Correlation between oral hygiene and periodontal condtion. Acta Odontol Scand 22, 121-135.
21. Cairo F, Rotundo R, Miller PD, Pini Prato GP (2009) Root coverage esthetic score: a system to evaluate the esthetic outcome of the treatment of gingival recession through evaluation of clinical cases. J Periodontol 80, 705-710.

22. Langer B, Langer L (1985) Subepithelial connective tissue graft technique for root coverage. J Periodontol 56, 715-720.

23. Lucchesi JA, Santos VR, Amaral CM, Peruzzo DC, Duarte PM (2007) Coronally positioned flap for treatment of restored root surfaces: a 6-month clinical evaluation. J Periodontol 78, 615-623.

24. Santamaria MP, da Silva Feitosa D, Casati MZ, Nociti FH Jr, Sallum AW, Sallum EA (2013) Randomized controlled clinical trial evaluating connective tissue graft plus resinmodified glass ionomer restoration for the treatment of gingival recession associated with non-carious cervical lesion: 2-year follow-up. J Periodontol 84, e1-8.

25. Rasperini G, Silvestri M, Schenk RK, Nevins ML (2000) Clinical and histologic evaluation of human gingival recession treated with a subepithelial connective tissue graft and enamel matrix derivative (Emdogain): a case report. Int $\mathrm{J}$ Periodontics Restorative Dent 20, 269-275.

26. Bruno JF, Bowers GM (2000) Histology of a human biopsy section following the placement of a subepithelial connective tissue graft. Int J Periodontics Restorative Dent 20, 225-231.

27. Santamaría MP, Suaid FF, Carvalho MD, Nociti FH Jr, Casati MZ, Sallum AW et al. (2013) Healing patterns after subgingival placement of a resin-modified glass-ionomer restoration: a histometric study in dogs. Int J Periodontics Restorative Dent 33, 679-687.

28. Gomes SC, Miranda LA, Soares I, Oppermann RV (2005) Clinical and histologic evaluation of the periodontal response to restorative procedures in the dog. Int J Periodontics Restorative Dent 25, 39-47.

29. Schätzle M, Land NP, Ånerud A, Boysen H, Bürgin W, Löe $\mathrm{H}$ (2001) The influence of margins of restorations of the periodontal tissues over 26 years. J Clin Periodontol 28, 57-64.

30. Larato DC (1972) Influence of a composite resin restoration on the gingiva. J Prosthet Dent 28, 402-404. 